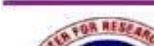 \\ APi: SPCRD GLOBAL PUBLISHING

\section{Review of Individual Differences through Ability-based Emotional Intelligence: An Examination of Resistance to Change}

\author{
${ }^{a}$ Ali Junaid Khan, ${ }^{b}$ Arslan Ayub, ${ }^{c}$ Tanveer Ahmed, ${ }^{b}$ Muhammad Akbar Ali Ansari \\ ${ }^{a}$ Institute of Business Management \& Administrative Sciences, The Islamia University of Bahawalpur, \\ Pakistan \\ Email: Junaaidkhan@yahoo.com \\ ${ }^{\mathrm{b}}$ Associate Professor, The University of Faisalabad, Pakistan \\ Email: drarslanayub@gmail.com \\ ${ }^{\mathrm{c}}$ Department of Environmental Management, National College of Business Administration \& Economics, \\ Lahore, Pakistan \\ Email: ranatanveer786@gmail.com \\ ${ }^{\mathrm{d}}$ Department of Commerce, The Islamia University of Bahawalpur, Pakistan \\ Email: makbar.ali@iub.edu.pk
}

\begin{tabular}{l}
\hline ARTICLE DETAILS \\
\hline History: \\
Accepted 22 January 2022 \\
Available Online January 2022 \\
\\
\hline Keywords: \\
Emotional Intelligence; Individual \\
Resistance to Change; Work \\
Outcomes; Age; Length of Service
\end{tabular}

JEL Classification:

J2O,L25

DOI: $10.47067 /$ ramss.v5i1.197

\begin{abstract}
This study investigates the sequential mediating effects of individual conflict on change and emotional intelligence between age and work outcomes, explained through the ability-based model of expressive intellect. In light of the increasingly diverse workforce, it is interestingly important to investigate individual differences in the context of organisational change. Thus, the study also aims to measure the association between age and individual conflict to alteration, considering the length of service as the moderating variable. The study collected data from 413 respondents working in the telecom sector in Punjab, Pakistan. SmartPLS (v 3.2.7) was employed to investigate the measurement model and the structural model. The findings revealed that individual resistance to change and emotional intelligence sequentially mediate the association between age and work results. Work also generates the moderating effect of service length with age and individual resistance to change. The study's limitations included a cross-sectional design, which prevents us from concluding causality. The study makes significant theoretical and practical contributions to organisational change management.
\end{abstract}

(C) 2022 The authors. Published by SPCRD Global Publishing. This is an open-access article under the Creative Commons Attribution-

NonCommercial 4.0

Corresponding author's email address: Junaaidkhan@yahoo.com 


\section{Introduction}

Institutional change management is the responsibility of everyone in the organization-from senior managers on down (LaClair \& Rao, 2002-while the change efforts might seem daunting (Ulrich et al., 2015). The rising pressure of the perpetual change transformation is rampant in this digital era's turbulent landscape. From the seminal work of John Kotter's "Leading Change" in 2009 to McKinsey's survey of 3,199 professionals in 2008 to date, tones of literary books and articles have witnessed around 70\% of the change transformations fail (e.g., Boardia \& DiFonzo, 2013; Cullen et al., 2014; Ewenstein et al., 2015; Kotter, 2009; LaClair \& Rao, 2002; Meaney \& Pung, 2008). Even large-scale organizational change is more elusive because large organizations are engaged in multiple change programs simultaneously (Ewenstein, 2015).

The literature revealed that employee resistance to change is the most prevalent factor in the impetus to organizational change failure (Ewenstein, 2015; Kunze et al., 2013).Since an organization endures perpetual change to an unprecedented degree, there is an incessant necessity to examine the impact of separate resistance to alteration on the work outcomes. Dent and Goldberg (1999) found that the staff fight mostly due to the distress of misplacing the work. Contrariwise, there are also counterintuitive insights, e.g., emotional reactions and cognitive rigidity, which are also central to resistance and determined by individual differences (Oreg, 2006). Thus, in the present study, the authors examine how individual differences overcome or leverage the counterintuitive insights of human behavior for understanding the organizational change phenomenon.

A massive stream of research suggests the following prescription that accounts for the success of the change programs: In this bracket, change communication (Boardia et al., 2004), wellplanned change (Rafferty \& Griffin, 2006), supposed administrative care (Cullen et al., 2014), and operational and executive involvement (Armenakis \& Harris, 2009) are central to the investigation. This prescription is well-grounded in the organizational change literature and is entirely rational. Nonetheless, there is a dearth of literature on the irrational side, i.e., the emotional side of organizational change (Aiken \& Keller, 2009).

The aims here are threefold. First, as discussed above, the current study investigates the association between separate conflicts' modification and work results. Second, the study proposes that an emotionally intelligent workforce induces the success of organizational change. This proposition is built on the impression that workers first undergo emotional change from the inside in order to spur institutional change, because the ability to adapt goes from feeling to reason. There is an extended agreement on the association between responsive intellect and work consequences, i.e., job satisfaction and job performance (Javeria et al., 2013; Sultana et al., 2016; Khan, Bhatti, Hussain, Ahmad, \& Iqbal, 2021). Despite its utmost importance, there is a missing link in the work of expressive intelligence in the context of administrative modification.

Third, to understand individual differences in the workplace, Bouman, Jong, and Janssen (2011) called for future studies to investigate the age differences in job characteristics and employees' reactions. Similarly, Sliter et al. (2013) also recommended exploring the association between age and expressive intelligence. As a result, the study makes use of age and length of service to gain a better understanding of individual differences in work outcomes. The study attempts to investigate the relationship between age and work outcomes via individual resistance to change and emotional intelligence by employing sequential mediation. We propose that high-aged people negatively relate to the resistance to change and positively relate to emotional intelligence and vice 
versa. Moreover, it also examines the contact consequence of length of service on the association of age and individual resistance to change. The study finally presents its theoretical contribution, research limitations, and future directions.

\section{Hypotheses}

\subsection{Age \& Work Outcomes}

The study of the relationship between age and effort results is well known in the field of organizational work (Ng \& Feldman, 2008; Wright \& Cropanzano, 2004). Studies have generally demonstrated an optimistic association between age and job performance and a bad association between age and job search behavior, perceived job alternatives, and turnover (Riordan, Griffith, \& Weatherly, 2003). Other studies have also found that highly aged employees are less likely to engage in job searching behavior and more likely to stay in the organization (Warr, 1995). Similarly, Mathieu and Zajac (1990) found in the metanalysis a positive association with an average correlation of 0.20 . Given the potential effect of age on work outcomes, it is hypothesized that:

H1. Age is completely connected to work outcomes.

\subsection{Individual Resistance to Change Acts as a Mediator}

The literature on resistance shows a blend of studies on the relationship between age and resistance to change (Kunze et al., 2013). In different cultural contexts, the following studies have found that high-aged employees are less adaptable to changing environments (Boumans et al., 2011; Posthuma, Wagstaff, \& Campion, 2012; Stein \& Monahan, 2007). The theoretical foundation underlying this key assumption can be viewed through the career stages model (Kunze et al., 2013). For instance, Pogson et al. (2003) defined the career stages model as:

1. (31 years old) Trial stage

2. Stage of stabilization (31-44 years old); and

3. Maintenance stage ( $>45$ years old)

According to Kunze et al. (2013), high-aged employees are more cognitively rigid since they are in the maintenance career stage. Due to their short-term focus, they tend to exhibit more resistance to change. In a metanalytical study, Finkelstein, Burke, and Raju (1995) found that highaged employees demonstrate low potential for development and higher degrees of stability, both of which result in increased resistance to change. Similarly, Kanfer and Ackerman (2004) found that high-aged employees prefer stable working conditions and they avoid organizational change because they perceive the relative loss of the usefulness of their experience.

Given the potential association between age and individual resistance to change, It is hypothesized that

H2. Age is negatively related to individual resistance to change.

Given prior conceptualizations and empirical research, the study proposes a negative relationship between age and individual resistance to change and a positive correlation between age and work outcomes. It is found that resistant employees have lower tendencies toward working effectively (Oreg, 2006; Sahabuddin et al., 2021). The motive may be attributable to the finding that high-aged employees prefer working in stable conditions interwoven into the physiological contract (Kiefer, 2005). However, organizational change initiatives that threaten the usefulness of the resources or status at work may result in experiencing a breach of the physiological contract with 
their organizations (Kunze et al., 2013). Similarly, individual resistance to change may question the relevance of personal control because of the change transition. In this situation, employees may experience powerlessness as they lack personal control. This line of inquiry is further endorsed by the previous studies that found lack of personal control negatively associated with job performance and job satisfaction. Given the effects of resistance as a result of the change, it is hypothesized that H3. Individual resistance to change mediates the relationship between age and work outcomes.

\subsection{Emotional Intelligence as a Mediator}

The study found that, an extensive theoretical framework supports the investigation of the relationship between age and emotional intelligence (Fernández-Berrocal et al., 2012). According to Kafesto (2004), a theoretical model of emotional intelligence as an ability is based in part on observation, and that this observation grows with time and experience. Mayer et al. (2002a, b) observed correlations between age and emotional intelligence ranging from 0.10 to 0.30 in a similar vein. The Mayer-Salovey-Caruso Emotional Intelligence Test was used in this study (MSCEIT). People who are older do somewhat better on all of MSCEIT's aspects, according to the data (Extremera et al., 2006). Emotional intelligence is also linked to age in a research by Goldenberg et al. (2006). As a result, it is speculated that

H4. Age is positively related to emotional intelligence.

According to the findings of the following research, there is a significant correlation between being older and having more emotional intelligence (Mayer, Salovey, \& Caruso, 1997; Van Rooy, Alonso, \& Viswesvaran, 2004). Due to lifelong learning, there is a positive correlation between age and emotional intelligence. It is evidenced that general intelligence, notably emotional intelligence (Sala, 2001), can be improved through practise (Hausknecht et al., 2007). Since high-aged people have more opportunity to practise emotional intelligence (Sliter et al., 2013), they gradually enhance their ability to understand their emotions and those of others they work closely with. It is correspondingly found that emotionally intelligent people report higher satisfaction and performance (Mayer et al., 2002a, b; Wong \& Law, 2002). Given the implications of age and emotional intelligence on work outcomes, it is therefore hypothesised that:

H5. Emotional intelligence mediates the relationship between age and work outcomes.

As noted above, high-aged employees resist organizational change due to cognitive rigidity (Kunze, 2013) because of the threat of a breach of the physiological contract with their companies (Kiefer, 2005), thereby leveraging a negative relationship between resistance and adaptability. The adverse effects of resistance to change can be appeased by exercising emotional intelligence. For instance, the literature on emotional intelligence contends that high-aged employees accumulate lifelong learning, which serves as a remedy to the resistance to change (Sliter et al., 2013). In addition, emotional intelligence is the precursor to the locus of control (Johnson et al., 2009). The following studies, including Di Fabio et al. (2014); and Vakola et al. (2004), further manifested the existence of a correlation between emotional intelligence and individual resistance to change. People with high control tend to exercise superior performance and higher satisfaction (Singh, 2006). Therefore, considering the underlying arguments, it is further hypothesized that:

H6. Individual resistance to change and emotional intelligence sequentially mediate the association between age and work outcomes. 


\subsection{Moderating Effect of Length of Service}

There has been a substantial nexus between length of service and individual resistance to change. Besides, length of service is the predominant factor that influences work outcomes (Wolfe \& Kim, 2013). For instance, Kunze et al. (2013) found that resistance to change is more pronounced for highly aged people with a long length of service than for highly aged people with a short length of service. Though accumulation of more years in the company results in increased task performance, at the same time, it inhibits one's ability to adapt. In response to organisational change, because of the shaken trust in their companies, employees withdraw their work efforts (Bateh, Castaneda, \& Farah, 2013). This happens because employees at different stages of their careers have different needs to be fulfilled (Huang et al., 2006). Generally, at an early age, employees with a short length of service have priorities regarding intrinsic characteristics of the job, task identity, job complexity, autonomy, etc. (Kunze et al., 2013). However, highly-aged employees with a long length of service exhibit more concern about conserving their gains. Therefore, it is further hypothesized that H7. Length of service moderates the relationship between age and individual resistance to change.

\section{Method}

\subsection{The Context of the Study}

Keeping in mind the long-term nature of the organizational change being studied, the study was performed in Pakistan's telecom market. The telecommunications industry in Pakistan is expanding at a rapid pace, making it more susceptible than any other industry to organizational change. As in any state, Pakistan's telecommunications sector is one of the most heavily impacted. Since 2005, mobile tele-density in this industry has increased by more than 300 percent (Telecom Indicators, 2014).1 billion people use mobile phones in Pakistan, making it one of the top ten nations in the world (Imtiaz et al., 2015). New technologies including 3G, 4G, LTE/Long Term Evolution, and 5G will necessitate large, tactical, and technological changes (PTA Annual Report 2018). As a result, creating and sustaining future leaders with effective change-implementing skills is indeed the true problem (Ulrich et al., 2015).

\subsection{Data Collection Methods and Strategies}

The study employed the positivist philosophical stance to explore the proposed theoretical framework. With the help of statistical tools, the authors examined the hypothesised relationships. A non-experimental correlational design was chosen with a survey strategy by utilising a face-to-face mode of data collection (Saunders et al., 2009). The study used structured and closed-end questionnaires. To increase the survey response rate, significant time was spent on developing the questionnaire and assessing the face validity of the constructs. To achieve this purpose, the researchers interviewed two consultants so that questionnaire understandability and the time to complete each survey could be confirmed. It took 30 minutes on average to complete one questionnaire. Additionally, the questionnaire was translated into Urdu for profound understanding and back-translated into English by a native English-speaking expert who is fluent in both languages.

At the next step, the researchers hired enumerators and provided detailed information about the content and context in particular. After that, the enumerators distributed 500 questionnaires in major cities in Punjab, Pakistan. 447 questionnaires were returned, and 413 questionnaires (after eliminating 34 incomplete questionnaires) were used for final analysis, leaving a response rate of 83\%. The demographics of respondents included 119 females and 292 males; less than 25 years were 67, between 26-35 years were 237, above 35 years were 101, and above 45 years were eight; the data 
for length of service represented $30 \%$ of respondents with less than 5 years and $67 \%$ of respondents with between 5 to 8 years.

\subsection{Accounting for Survey Method Bias}

Self-reported measures were used in this cross-sectional study. Using Harmon's One-Factor test, we were able to account for the common method bias (CMB), one of the problems with selfreported measures (Podsakoff et al., 2003). Cytomegalovirus isn't a factor in this study's findings, since the maximum variance described by a single component is 33.107 percent, which should be just under 50 percent (Podsakoff et al., 2003).

\subsection{Measures}

Consistent with the study objectives, in addition to the single-item variables, i.e., age and length of service, the study assessed individual resistance to change and emotional intelligence. We used a Likert scale with a maximum of 5 points, with 1 representing "strongly disagree" and 5 representing "strongly agree." The following are the specifics of the instrumentalization:

\subsection{Individual Resistance to Change}

Individual resistance to change was measured using the 10-item scale adapted from Oreg (2006). Two of the most relevant dimensions, i.e., emotional reactions and cognitive rigidity, were utilized to determine individual resistance to change. There were 6 items to measure emotional reactions and 4 items to measure cognitive rigidity.

\subsection{Emotional Intelligence}

The Mayer and Salovey (1997) model of ability-based emotional intelligence competency was used to test emotional intelligence. For the study, the Wong and Law Emotional Intelligence Scale (WLEIS) was adapted from the Chinese context to accommodate for cultural variations with credible proximity to our own local culture in Western countries (Sultana et al., 2016). Each of the model's four limbs was measured using one of the scale's 16 elements.

The dependent variable in this study was work outcome, which was measured through job satisfaction and job performance. It contained 20-items, with 14-items measuring job satisfaction (Hackman \& Oldham, 1974) and six items measuring job performance (Becker et al., 1996). Moreover, job performance was measured using supervisor rating to avoid self-serving bias (Podsakoff et al., 2003).

\section{Results}

The study assessed the proposed theoretical framework using SmartPLS (v 3.2.7) through path modelling, considering two assumptions, i.e., its ability to measure Relationships that are both complex and non-normal distribution in nature (Hair et al., 2017). First, the measurement model was evaluated, and then the structural model was evaluated, using PLS-SEM. Internal consistency, indicator reliability, convergent validity, and discriminant validity were all considered while evaluating the measurement model (Henseler et al., 2009). Table 1 shows the psychometric properties and constructs correlations for the measurement model. Factor loadings were used to evaluate the reliability of the various items on the manifest variables (indicators) scale. Eighteen indicators were eliminated from the final analysis because their loadings were less than 0.55. As shown in Table 1, the convergent validity AVE and the discriminant validity HTMT ratio of Cronbach's alpha, composite reliability, and average extracted variance (Hair et al., 2017). For 
internal consistency, a composite reliability index was used. In our study, all values exceeded the minimum acceptable threshold value of 0.7 (Hair et al., 2017), with individual resistance to change the lowest (0.823). Table 1 also shows AVE scores above the acceptable value, ranging from 0.438 for individual resistance to change to 0.575 for emotional intelligence (Henseler et al., 2009). If you're trying to determine psychometric properties, Hair and coworkers recommend using the HTMT associations proportion instead of the Fornell-Larcker and cross-loading methods. HTMT.90 is the appropriate lower limit for HTMT.90 with a 95\% standard error in table 1 of our study results. Because one test is the foundation of HTMT inference As a result, we used a 90\% built from scratch standard error to ensure that there were no confirmatory factor concerns in our study (Henseler et al., 2015).According to Hair et al., the appropriate threshold for assessing multicollinearity is 5 . Nevertheless, (VIFs) varied from 1.000 to 3.30 , and everybody was below the appropriate standard of 5. (2017).

Table 1 Psychometric Properties and Construct Correlation

\begin{tabular}{|c|c|c|c|c|c|c|c|}
\hline Constructs & $\begin{array}{l}\text { Cronbach's } \\
\text { Alpha }\end{array}$ & $\begin{array}{l}\text { Composite } \\
\text { Reliability }\end{array}$ & AVE & Age & EI & IRC & Wo \\
\hline Age & 1.000 & 1.000 & 1.000 & & & & \\
\hline EI & 0.925 & 0.937 & 0.575 & $\begin{array}{l}0.518 \\
\mathrm{CI}_{.900} \\
{[0.473 ; 0 .} \\
555]\end{array}$ & & & \\
\hline IRC & 0.758 & 0.823 & 0.438 & $\begin{array}{l}0.227 \\
\mathrm{CI}_{.900} \\
{[0.159 ; 0 .} \\
294]\end{array}$ & $\begin{array}{l}0.582 \\
\mathrm{CI}_{.900} \\
{[0.501 ; 0 .} \\
650]\end{array}$ & & \\
\hline Wo & 0.913 & 0.927 & 0.538 & $\begin{array}{l}0.515 \\
\mathrm{CI}_{.900} \\
{[0.468 ; 0 .} \\
560]\end{array}$ & $\begin{array}{l}0.884 \\
\mathrm{CI}_{.900} \\
{[0.849 ; 0 .} \\
911]\end{array}$ & $\begin{array}{l}0.664 \\
\mathrm{CI}_{.900} \\
{[0.596 ; 0 .} \\
726]\end{array}$ & \\
\hline
\end{tabular}

Note: $\mathrm{EI}=$ Emotional Intelligence, $\mathrm{WO}=$ Work Outcomes, $\mathrm{IRC}=$ Individual Resistance to Change. Values in bold are HTMT $^{\text {inference }}$ ratio

It is possible to use a conceptual framework to look at the relationships among factor loadings (see table 2). The intensity of the route coefficients and the overall restrictiveness (R2) of the external components are used to determine the quality of the conceptual perspective, which is predominantly predicted by PLS-SEM (Hair et al., 2017). The process of starting with 5,0oo routines of the structure route was used to examine using the t-value of the PLS-SEM. Hensel et al. (2015) describe a non-parametric technique used to estimate the precision of the structural path. Values close to one indicate the path's strength; however, values of 0.2 and 0.3 are usually considered significant when accompanied by R2 values greater than 0.5 (Hair et al., 2017). In this research, there was a minor, moderate, and considerable influence on resistance to change based on coefficients of determination (R2), with variance explained by $26.1 \%$, emotional intelligence with variance explained by $45.1 \%$, and work outcomes with variance explained by $78.4 \%$. 
In place of hypothesis 1 , the total effect of age on job outcomes was significant $(=0.368, t=$ 11.014, $\mathrm{p}$ 0.001), as was the total direct effect without the effect of mediating variables $(=0.125, \mathrm{t}=$ 3.915, p 0.001).Similarly, age had significant direct effects on individual resistance to change $(=-$ $0.241, \mathrm{t}=4.935, \mathrm{p}$ 0.001) and emotional intelligence $(=0.388, \mathrm{t}=11.706, \mathrm{p}$ 0.001 $)$, consistent with hypotheses 2 and 4. The total indirect effect (the sum of specific indirect effects) was significant (= $0.368, \mathrm{t}=11.014$, p 0.001), with a 95\% confidence interval ranging from 0.298 to 0.426 . According to hypotheses 3 and 5 , the specific indirect effects for the mediation of individual resistance to change $(=0.064, \mathrm{t}=4.479, \mathrm{p} 0.001)$ and emotional intelligence $(=0.236, \mathrm{t}=8.800, \mathrm{p}$ o.001 $)$ were significant.

Table 2 Tests of Direct and Indirect Effects

\begin{tabular}{|c|c|c|c|c|}
\hline Effects & Coefficient & 95\% BCa CIs & t value & $\mathbf{p}<0.05$ \\
\hline \multicolumn{5}{|l|}{ Direct Effect } \\
\hline AgeПIRC & -0.241 & {$[-0.322 ;-0.125]$} & 4.935 & 0.000 \\
\hline Age[EI & 0.388 & {$[0.328 ; 0.454]$} & 11.706 & 0.000 \\
\hline Age[WO & 0.125 & {$[0.066 ; 0.190]$} & 3.915 & 0.000 \\
\hline IRCEI & -0.461 & {$[-0525 ;-0.360]$} & 10.841 & 0.000 \\
\hline IRCWWO & -0.268 & {$[-0.337 ;-0.193]$} & 7.124 & 0.000 \\
\hline EITWO & 0.609 & {$[0.516 ; 0.700]$} & 12.990 & 0.000 \\
\hline \multicolumn{5}{|l|}{ Indirect Effect } \\
\hline AgeШRCWWO & 0.064 & [0.035; 0.090] & 4.479 & 0.000 \\
\hline AgeEEITWO & 0.236 & {$[0.191 ; 0.300]$} & 8.800 & 0.000 \\
\hline AgeШIRCEIIWO & 0.068 & [0.034; 0.099] & 3.883 & 0.000 \\
\hline
\end{tabular}

Consistent with hypothesis 6 , the specific indirect effect on the relationship between age and work outcomes via individual resistance to change and emotional intelligence was significant (= o.068, $\mathrm{t}=3.883, \mathrm{p}$ o.001)., the findings lend support to all the hypothesised relationships in this study.

According to hypothesis 7 , the moderating influence of the moderator is represented by relationships pointing to the endogenous variable and a direct relationship between the moderator and the variable. (As seen in Figure 1). Our main goal was to shed light on the moderating effect's importance. The two-stage procedure recommended by was thus used by (Henseler et al., 2015). Also, when the construct and the moderator are measured formatively, then the two-stage approach is the method of choice (Hair et al., 2017). The first step is to determine the size of the moderating effect. While age alone has a negative influence on individual resistance to change (o.ogo), the combination of age and time in service (0.151) has a positive effect. Figure 2 shows the graphical representation of the interaction effect. The analysis revealed that length of service moderates the relationship between age and individual resistance to change. For instance, highly aged employees with a long length of service are related to increased resistance to change and vice versa. Thus, the interaction effect has confirmed hypothesis 7 . 


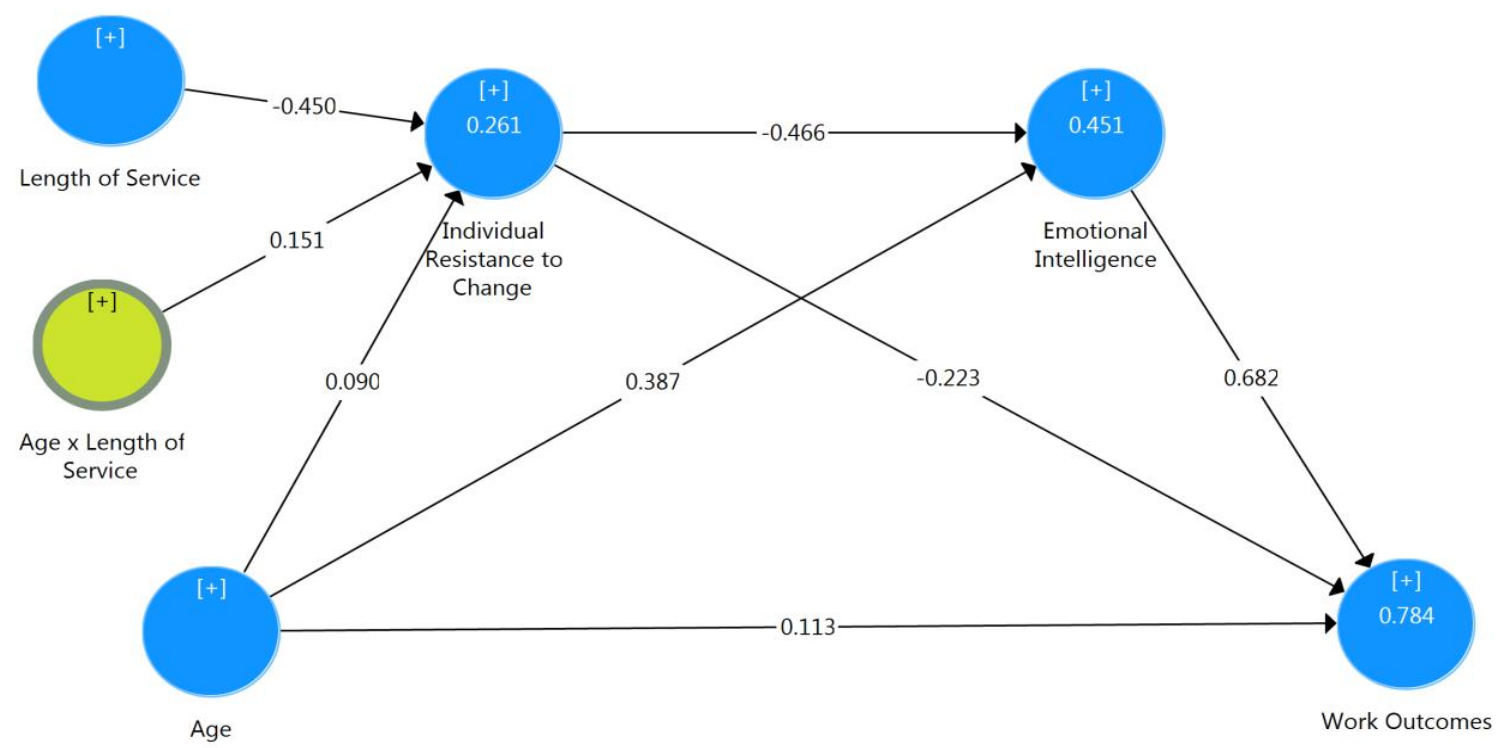

Figure 1 Sequential Mediation Model with Individual Resistance to Change and Emotional Intelligence as proposed mediators of age to work outcomes and length of service as moderator

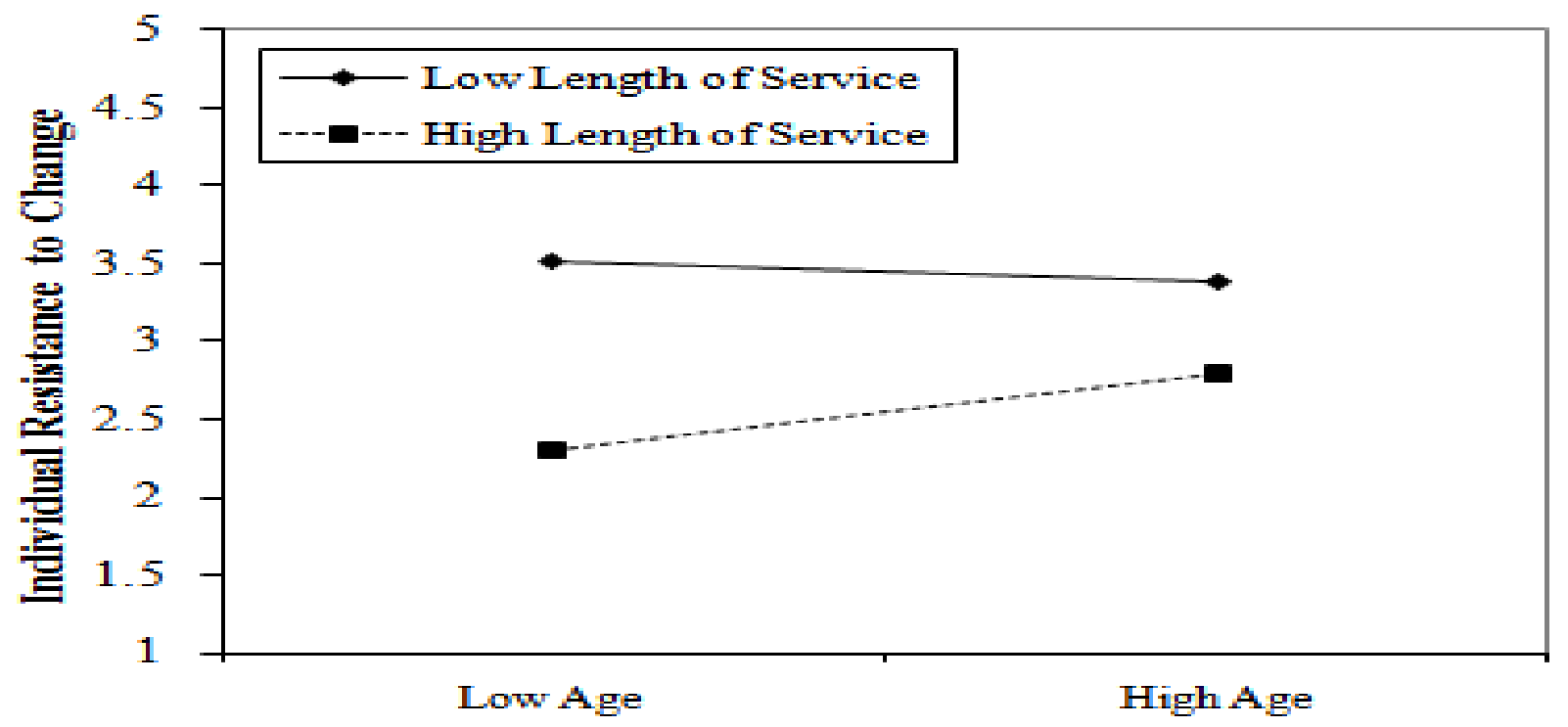

Figure 2 Interaction Effect with Length of Service as proposed moderator of Age and Individual Resistance to Change

\section{Discussion}

Individual variables such as age and length of service were taken into account while examining the effect of emotional intelligence on the link between reluctance to change on the part of the individual and job results. An increasing number of studies have found a link between organisational resistance to change and the inability to implement change (e.g., Bordia et al., 2004; Oreg, 2006). For example, Oreg (2006) discovered a negative correlation between resistance and two personality qualities: openness to new experiences and tolerance of ambiguity (both of which positively predict performance). According to the findings of Kunze et al. (2013), employees who exhibit a high degree of resistance to innovation have more difficulty meeting their performance objectives. Individual resistance to change was found to have a negative correlation with goal 
success. Because of this, the study discovered a negative correlation between individual resistance to change and work productivity (Rasool, Asghar, Gill, \& Khan, 2021).

Individuals may experience a certain amount of uncertainty when an organisation undergoes a major shift in its structure. Dent and Goldberg (1999) discovered, however, that employees resisted because they were afraid of losing their jobs. Another reason why workers reject organisational change is because of their cognitive rigidity and emotional reactivity. As a result, the hypothesised association between emotional intelligence and resistance to change was more accurately predicted. In several studies, emotional intelligence has been linked to a reluctance to change.

Individuals who have resistant to change have lower emotional intelligence. According to Personal tolerance to transition and emotional intelligence were shown to be inversely related, according to Vakola et al. (2004), who also looked at the link between the two variables. In other words, both theoretical and empirical research support the idea that EQ serves as a mediator between people's aversion to change and their professional success.

The review of the literature reveals that the hypothesised relationship between age and work outcomes tends to be of a modest magnitude (Riordan et al., 2003). In response, theorists suggest investigating this rapport in a more complex relationship (Kunze et al., 2013). Following this advice, several studies have found significant moderating influences on age and work-outcome relationships (Riordan et al., 2003). For instance, job type, type of occupation (Avolio, Waldman, \& McDaniel, 1990), job design (Schwoerer \& May, 1996), and training have found moderating effects of these variables on the relationship between age and work outcomes. The current study is, therefore, unique in this perspective in that we investigated this relationship through sequential mediation in the presence of the length of service as the moderating variable.

\section{Limitations and Future Directions}

To begin, there is a dearth of research on the subject of emotional intelligence and organisational transformation. For this study, the ability-based emotionally intelligent competency was measured by Wong and Law Expressive Awareness Scale (WLEIS), which was used due to societal disparities between West and non-western nations (Wong \& Law, 2002). However, the Mayer et al. (1997) and Mayer-Salovey-Caruso (v 2) Emotional Intelligence Test (MSCEIT) (v 2), developed by Mayer and Salovey, show that emotional intelligence can be measured. Other studies may make use of the Multivariate Regression Emotional Intelligence Scale (MEIS). The ability-based paradigm was also used to assess participants' levels of emotional intelligence.

However, in the context of organisational transformation, research studies may use traitbased and/or mixed emotional intelligence measures to study individual variations in a more robust manner. Second, the current study aims to establish a connection between age, individual resistance to change, emotional intelligence, and job results. Considering that this was the first study of its kind, the major goal of the research was to develop a theoretical model and investigate how various factors interacted. This study used PLS-SEM since it primarily wants to investigate the idea. Due to the fact that PLS-SEM is also a non-parametric measurement, data analysis does not take distributional assumptions into account (Hair et al., 2017).

Expanding this study's breadth and testing the theoretical model in a larger and more rigorous research design are necessary for future investigations. CB-SEM should thus be used to 
validate or reject ideas that are outside the scope of the PLS-SEM research. In addition, the goodnessof-fit index is provided by CB-SEM (GoF). Due to this, PLS-shortcomings SEM's can be leveraged by PLS-lack SEM's of trustworthy measures for measuring fit.

A non-experimental correlational survey approach was used in this study, which is why the results are not statistically significant. Data gathering in this study was influenced by a positive philosophical perspective (Saunder et al., 2009). Therefore, future studies may use a survey technique (i.e. time-lagged data, combined statistical study) or a mix of both descriptive and inferential statistical research. Experiments can be used to better understand the variations between individuals.

\section{Conclusion}

The study was undertaken primarily to assess the predictive ability of the proposed theoretical agenda on the relationship between age, separate conflict to alteration, emotional intelligence, and effort results. The study also aimed to measure the role of emotional intelligence as a plausible feature in the association between separate conflict alteration and effort results. According to the findings, there is partial mediation between age, individual conflict to alteration, and effort outcomes, as well as age, emotional intelligence, and effort outcomes. The study also found that individual resistance to change and emotional intelligence sequentially mediate the relationship between age and work outcomes. Overall, the results of this study support the transformation of the workforce irrationally, i.e., the study recommends that organisations can leverage change through an emotionally intelligent workforce. Moreover, the length of service was found to be a significant moderating variable between age and individual resistance to change.

\section{References}

Aiken, C., \& Keller, S. (2009). The irrational side of change management. McKinsey Quarterly, 2(10), 100-109.

Armenakis, A. A., \& Harris, S. G. (2009). Reflections: Out journey in organizational change research and practice. Journal of Change Management, 9, 127-142.

Authority, P. T. (2018). Pakistan Telecommunication Authority, 2018 Annual Report.

Avolio, B. J., Waldman, D. A., \& McDaniel, M. A. (1990). Age and work perfor- mance in nonmanagerial jobs: The effects of experience and occupational type. Academy of Management Journal, 33,407-422.

Bateh, J., Castaneda, M. E., \& Farah, J. E. (2013). Employee resistance to organizational change. International Journal of Management \& Information Systems (Online), 17(2), 113.

Becker, T. E., Billings, R. S., Eveleth, D. M., \& Gilbert, N. L. (1996). Foci and bases of employee commitment: Implications for job performance. Academy of management journal, 39(2), 464482.

Bordia, P., \& DiFonzo, N. (2013). 10 Rumors during organizational change: a motivational analysis. The Psychology of Organizational Change: Viewing Change from the Employee's Perspective, 232.

Bordia, P., Hunt, E., Paulsen, N., Tourish, D., \& DiFonzo, N. (2004). Uncertainty during organizational change: Is it all about control?. European Journal of Work and Organizational Psychology, 13(3), 345-365.

Boumans, N. P., De Jong, A. H., \& Janssen, S. M. (2011). Age-differences in work motivation and job satisfaction. The influence of age on the relationships between work characteristics and workers' outcomes. The International Journal of Aging and Human Development, 73(4), 331- 
350.

Cullen, K. L., Edwards, B. D., Casper, W. C., \& Gue, K. R. (2014). Employees' adaptability and perceptions of change-related uncertainty: Implications for perceived organizational support, job satisfaction, and performance. Journal of Business and Psychology, 29(2), 269280.

Dent, E. B., \& Goldberg, S. G. (1999). Challenging "resistance to change". The Journal of applied behavioural science, 35(1), 25-41.

Di Fabio, A., Bernaud, J. L., \& Loarer, E. (2014). Emotional intelligence or personality in resistance to change? Empirical results in an Italian health care context.journal of employment counseling, 51(4), 146-157.

Ewenstein, B., Smith, W., \& Sologar, A. (2015). Changing change management. McKinsey Digital, 1-4. Extremera, N., Fernández-Berrocal, P., \& Salovey, P. (2006). Spanish Version of the MayerSaloveyCaruso Emotional Intelligence Test (MSCEIT) Version 2.0: Reliabilities, Age, and Gender Differences. Psicothema, 18, 42-48.

Fernández-Berrocal, P., Cabello, R., Castillo, R., \& Extremera, N. (2012). Gender differences in emotional intelligence: The mediating effect of age. Behavioral Psychology/Psicología Conductual, 20(1), 77-90.

Finkelstein, L. M., Burke, M. J., \& Raju, M. S. (1995). Age discrimination in simulated employment contexts: An integrative analysis. Journal of applied psychology, 8o(6), 652.

Goldenberg, I., Matheson, K., \& Mantler, J. (2006). The assessment of emotional intelligence: a comparison of performance-based and self-report methodologies. Journal of Personality Assessment, 86, 33-45.

Hackman, J. R., \& Oldham, G. R. (1974). The job diagnostic survey: An instrument for the diagnosis of jobs and the evaluation of job redesign projects.

Hair, J. F., Hult, G. T. M., Ringle, C. M., \& Sarstedt, M. (2017). A primer on partial least squares structural equation modelling (PLS-SEM), Sage Publicaitons, Thousand Oaks, CA.

Hausknecht, J. P., Halpert, J. A., Di Paolo, N. T., \& Moriarty, M. O. (2007). Retesting in selection: A meta-analysis of practice effects for tests of cognitive ability. Journal of Applied Psychology, 92, 639-683.

Henseler, J., Ringle, C. M., \& Sarstedt, M. (2015). A new criterion for assessing discriminant validity in variance-based structural equation modeling. Journal of the academy of marketing science, 43(1), 115-135.

Henseler, J., Ringle, C. M., \& Sinkovics, R. R. (2009). The use of partial least squares path modeling in international marketing. In New challenges to international marketing (pp. 277-319). Emerald Group Publishing Limited.

Huang, X., Shi, K., Zhang, Z., \& Cheung, Y. L. (2006). The impact of participative leadership behavior on psychological empowerment and organizational commitment in Chinese state-owned enterprises: the moderating role of organizational tenure. Asia Pacific Journal of Management, 23(3), 345-367.

Imtiaz, S. Y., Khan, M. A., \& Shakir, M. (2015). Telecom sector of Pakistan: Potential, challenges and business opportunities. Telematics and Informatics, 32(2), 254-258.

Javeria, A., Rizwan, M., Khan, A., Hameed, A., Neem, Q., \& Subctageen, M. (2013). Examining the Antecedents of Job Satisfaction and further its impact on Organizational Commitment. Journal of Public Administration and Governance, 3(3), 317-334.

Johnson, S. J., Batey, M., \& Holdsworth, L. (2009). Personality and health: The mediating role of trait emotional intelligence and work locus of control. Personality and Individual Differences, 47(5), 470-475.

Kafetsios, K. (2004). Attachment and emotional intelligence abilities across the life course. 
Personality and Individual Differences, 37, 129-145.

Kanfer, R., \& Ackerman, P. L. (2004). Aging, adult development, and work motivation. Academy of management review, 29(3), 440-458.

Kiefer, T. (2005). Feeling bad: Antecedents and consequences of negative emotions in ongoing change. Journal of Organizational Behavior: The International Journal of Industrial, Occupational and Organizational Psychology and Behavior, 26(8), 875-897.

Khan, A. J., Bhatti, M. A., Hussain, A., Ahmad, R., \& Iqbal, J. (2021). Employee Job Satisfaction in Higher Educational Institutes: A Review of Theories. Journal of South Asian Studies, 9(3).

Khan, A. J., Tufail, S., \& Ali, A. (2021). Factors Affecting Performance of Small \& Medium Enterprises: The Mediating Role of Knowledge Management. Pakistan Journal of Humanities \& Social Sciences, 9(2), 197-209. doi:https://doi.org/10.52131/pjhss.2021.0902.0129

Kotter, J. P. (2009). Leading change: why transformation efforts fail. Harvard Business Review, $73(2)$.

Kunze, F., Boehm, S., \& Bruch, H. (2013). Age, resistance to change, and job performance. Journal of Managerial Psychology, 28(7/8), 741-76o.

LaClair, J. A., \& Rao, R. P. (2002). Helping Employees Embrace Change. McKinsey Quarterly, 17-22.

Mathieu, J. E., \& Zajac, D. M. (1990). A review and meta-analysis of the antecedents, correlates, and consequences of organizational commitment. Psychological bulletin, 108(2), 171.

Mayer, J. D., Salovey, P., \& Caruso, D. R. (1997). Emotional IQ test (CD ROM). Needham, MA: Virtual Knowledge.

Mayer, J. D., Salovey, P., \& Caruso, D. (2002a). Mayer-Salovey-Caruso Emotional Intelligence Test (MSCEIT), version 2.o. Toronto: Multi-Health Systems.

Mayer, J. D., Salovey, P., \& Caruso, D. R. (2002b). Mayer-Salovey-Caruso Emotional Intelligence Test (MSCEIT): User's manual. North Tonawanda, New York: Multi-Health Systems, Inc.

Mayer, J. D., \& Salovey, P. (1997). What is emotional intelligence? In P. Salovey \& D. J. Sluyter (Eds.), Emotional development and emotional intelligence: Educational implications (3-31). New York, NY: Basic Books.

Meaney, M., \& Pung, C. (2008). McKinsey global results: Creating organizational transformations. The McKinsey Quarterly, 7(3), 1-7.

Ng, T. W., \& Feldman, D. C. (2008). The relationship of age to ten dimensions of job performance. Journal of applied psychology, 93(2), 392.

Oreg, S. (2006). Personality, context, and resistance to organizational change. European journal of work and organizational psychology, 15(1), 73-101.

Podsakoff, P. M., MacKenzie, S. B., Lee, J. Y., \& Podsakoff, N. P. (2003). Common method biases in behavioural research: A critical review of the literature and recommended remedies. Journal of applied psychology, 88(5), 879.

Pogson, C. E., Cober, A. B., Doverspike, D., \& Rogers, J. R. (2003). Differences in self-reported work ethic across three career stages. Journal of vocational behavior, 62(1), 189-201.

Posthuma, R. A., Wagstaff, M. F., \& Campion, M. A. (2012). 16 Age Stereotypes and Workplace Age Discrimination. The Oxford handbook of work and aging, 298.

Rafferty, A., \& Griffin, M. (2006). Perceptions of organizational change: A stress and coping perspective. Journal of Applied Psychology, 91, 1154-1162

Riordan, C. M., Griffith, R. W., \& Weatherly, E. W. (2003). Age and work-related outcomes: the moderating effects of status characteristics. Journal of Applied Social Psychology, 33(1), 37-57.

Sala, F. (2001). Do programs designed to increase emotional intelligence at work? Consortium for Research on Emotional Intelligence in Organizations. Retrieved from www.eiconsortium.org (July 11, 2012). 
Saunders, M., Lewis, P., \& Thornhill, A. (2009). Research methods for business students. Pearson education.

Schwoerer, C. E., \& May, D. R. (1996). Age and work outcomes: The moderating effects of selfefficacy and tool design effectiveness. Journal of Organizational Behavior, 17,469-487.

Singh, S. K. (2006). Social work professionals' emotional intelligence, locus of control and role efficacy: an exploratory study. South African Journal of Human Resource Management, 4, 3945.

Sliter, M., Chen, Y., Withrow, S., \& Sliter, K. (2013). Older and (emotionally) smarter? Emotional intelligence as a mediator in the relationship between age and emotional labor strategies in service employees. Experimental Aging Research, 39(4), 466-479.

Steinberg, L., \& Monahan, K. C. (2007). Age differences in resistance to peer influence. Developmental psychology, 43(6), 1531.

Sultana, R., Yousaf, A., Khan, I., \& Saeed, A. (2016). Probing the interactive effects of career commitment and emotional intelligence on perceived objective/subjective career success. Personnel Review, 45(4), 724-742.

Telecom Indicators. (2014). Pakistan Telecommunication Authority (PTA), May 2014 Available: http://pta.gov.pk/.

Ulrich, D., GPHR, W. A. S., SPHR, A. S. D., HRMP, J. J. M., \& SPHR, L. S. (2015). The rise of HR: Wisdom from 73 thought leaders. HR Certification Institute.

Vakola, M., Tsaousis, I., \& Nikolaou, I. (2004). The role of emotional intelligence and personality variables on attitudes toward organisational change. Journal of managerial psychology, 19(2), 88-110.

Van Rooy, D. L., \& Viswesvaran, C. (2004). Emotional intelligence: a meta-analytic investigation of predictive validity and nomological net. Journal of Vocational Behaviour, 65, 71-95.

Wanberg, C. R., \& Banas, J. T. (2000). Predictors and outcomes of openness to changes in a reorganizing workplace. Journal of Applied Psychology, 85, 132-142.

Warr, P. (1995). Age and job performance. Snel, J., Cremer, R.(Hg.)(1995): Work and aging. An European perspective, S, 309-322.

Wolfe, K., \& Kim, H. J. (2013). Emotional intelligence, job satisfaction, and job tenure among hotel managers. Journal of Human Resources in Hospitality \& Tourism, 12(2), 175-191.

Wong, C. S., \& Law, K. S. (2002). The effects of leader and follower emotional intelligence on performance and attitude: An exploratory study. The leadership quarterly, 13(3), 243-274.

Wright, T. A., \& Cropanzano, R. (2004). The role of psychological well-being in job performance: a fresh look at an age-old quest. Organizational Dynamics, 33(4), 338-351. 